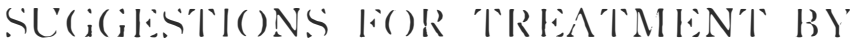 PHYSICAI, METIOUIS IN NEURAL, IEPROSY'
}

Ruth E. Thomas, s.r.N., M.C..s:P.

Physiotherapy is a comparatively new line of treatment where leprosy is concerned, and for it to be successful the psychological outlook of the patient is of the utmost importance. Many patients who have some paralytic trouble of the hand or cleformity of the fingers give un their work when this paralysis or rleformity begins, or shortly after it commences. This may be (lue to the fact that the patient himself feels this weakness and therefore feels he can no longer cope with his work, or it is sometimes because his employer has no use for a person with weak hancls; or (and this seems the worst reason of all from the psychological aspect of the patient) it is sometimes because no one will employ a person with leprosy. But, whatever the reason, the fact that the patient has had to give II) his work tends to make him feel he is no use to himself or anyone else, and that he is a burden to his family and society, with the result that he resigns himself to his condition and loses the will to help himself.

The main aim, therefore, is to win the confidence and co. operation of these people, and try to help them to help themselves, and to show them that weak or deformed though their hands may be they can, with care and practice, do much to help themselves. They must learn to realise that they cannot do many things as well as the normal person, and that their movements are necessarily slower because of thcir disability. In some way they must be taught to accept all this, and at the same time be encouraged to use what is left; and to learn that there are many things that they can, with practice, get to do as well as a perfectly normal person; the important point being not to give them anything to do which is beyond their capabilities, or they will become discouraged rather than encouraged.

For two years several methods of physiotherapy have been used on a number of patients with varying degrees of paralysis and deformity at the Leprosy Clinic of Vellore Christian Medical College Hospital, South India. Careful records have been kept, and the results seem to indicate that physiotherapy is of great value in neural leprosy. This article has been written with a view to stimulating other Leprosy Sanatoria to introduce some of the treatments as a routine measure.

It has been found that short courses of treatment (e.g. less than three months) are not sufficient to benefit the patient. I.ong courses 
of treatment (at least $3^{-(t)}$ months, preferably longer) are necessary if physiotherapy is to be of value to the patient.

\section{ELECTRICAL, STIMLIATION.}

\section{Requirements :-}

Faradic Unit:- Smart-Bristow type is recommencled. (This is not dependent on the main supply, but is fitted with dry cells.)

2 rubber covered wires, each about $3 \mathrm{ft}$. in length.

I metal plate electrode $3 " \times 2 "$, and I lint pad $4 " \times 3 "$.

I disc electrode not more than ${ }_{2}^{1 "}$ in cliameter.

I bowl for warm water.

I mackintosh for covering the table.

MiThOD :-

I. The wires are attached to the 2 terminals of the laradic Unit.

2. To the other ends of the wires are attached the metal plate electrode to one, and the disc electrocle to the other.
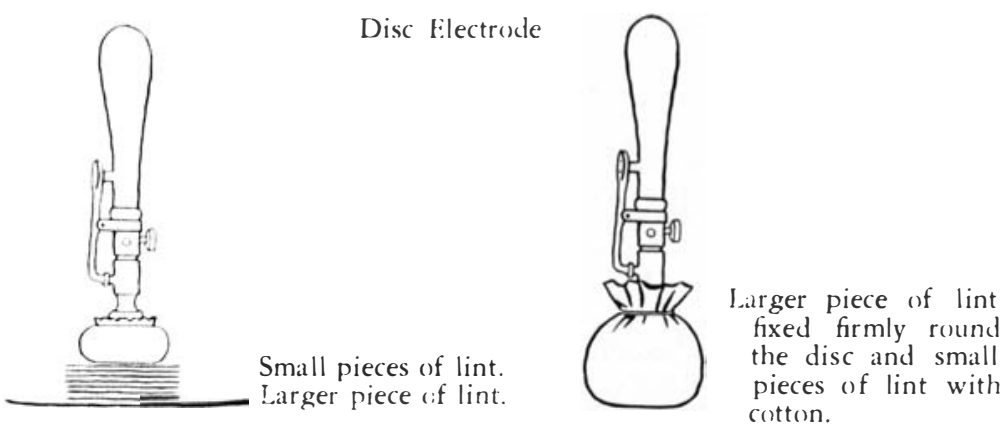

3. The disc electrode should be well padded with several layers of lint to minimise sensory stimulation when applied to the patient.

4. The piece of lint used for the pad should measure I2" x I6", and should be folded with the edges facing inwards till there are I6 thicknesses of lint-about $\frac{1}{2}$ " thickness.

FIG. (a) Piece of lint for pad.

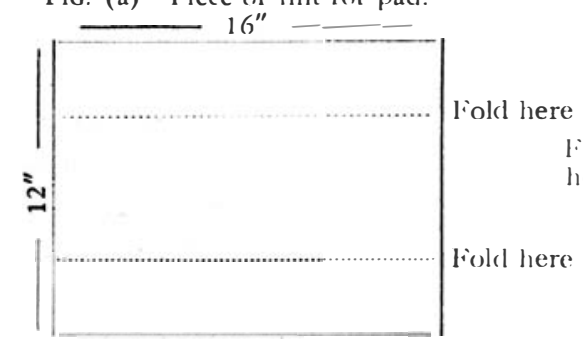

FIG. (b)

FIG. (c)

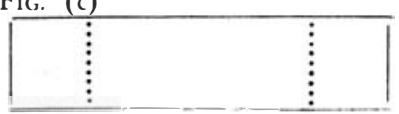

Fold here

Fold here

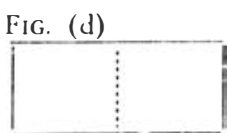

liold here
FIG. (e)

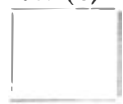

Pad ready for use. 
5. The pad is then immersed in the water, and allowed to remain in it till thoroughly soaked. "Then it is squeezed fairly firmly so that it cloes not (lrip) water, but it must not be sefueered till it is too dry. The pad and plate electrode are then placed in the position repuired, the pad being between the skin and the electrocle, ancl are known as the "inclifferent" electrode:-

(a) For treating flexor muscles of the forearm with the disc electrode, the pad and plate electrode are placed on the table with the extensor aspect of the forearm resting on it.

(b) fior treating the extensor muscles of the forearm with the clisc electrode the pad and plate electrocle are placed on the table with the flexor aspect of the forearm resting on it.

(c) For treating the clorsal interossei the palm of the hand is placed on the pad.

(c) For treating the intrinsic muscles of the palm of the hand the dorsum of the hand is placed on the pad.

0. The clisc electrode is known as the active electrocle and it can be used either (a) for stroking firmly up and down the forearm, thus working the different muscles in turn or (b) for picking out the motor point of each muscle and treating each muscle separately for 6-1 2 times.

Motor points of the Left forearm and Hand

(a) Anterior ispect.

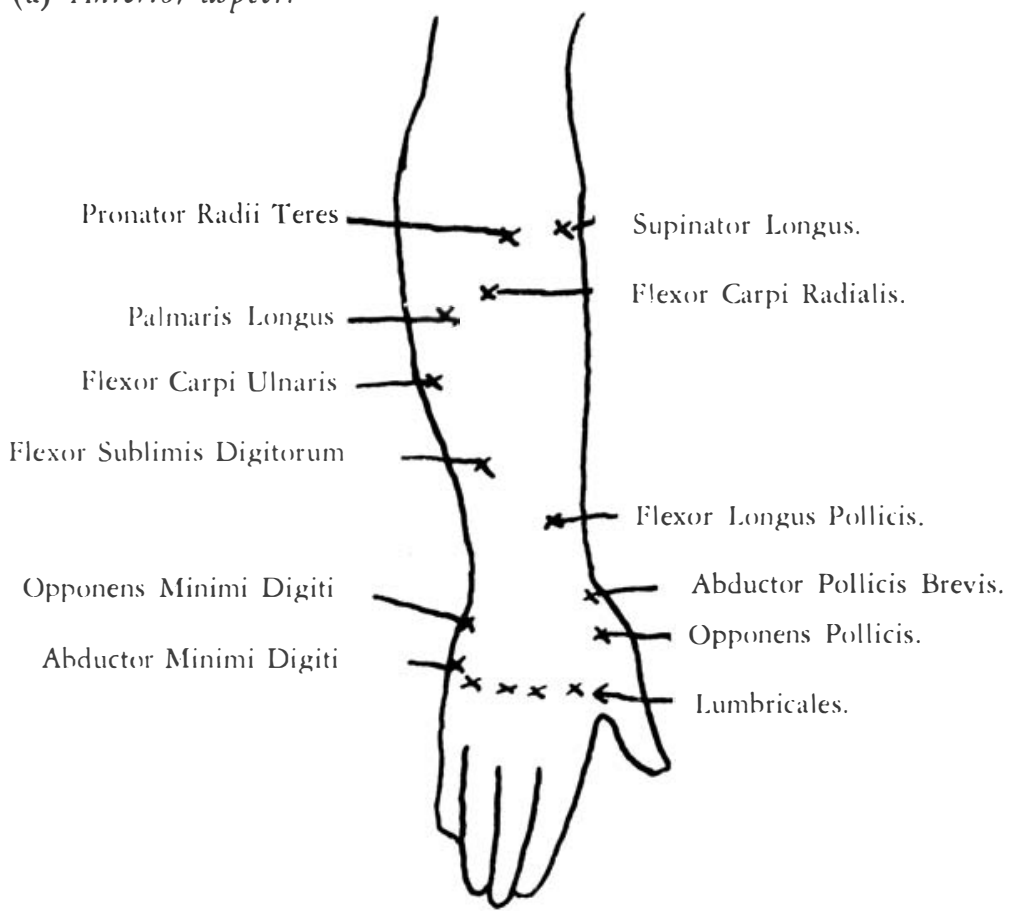


Wotor points of the left liovearm and Hand

(b) Posterior Aspect:

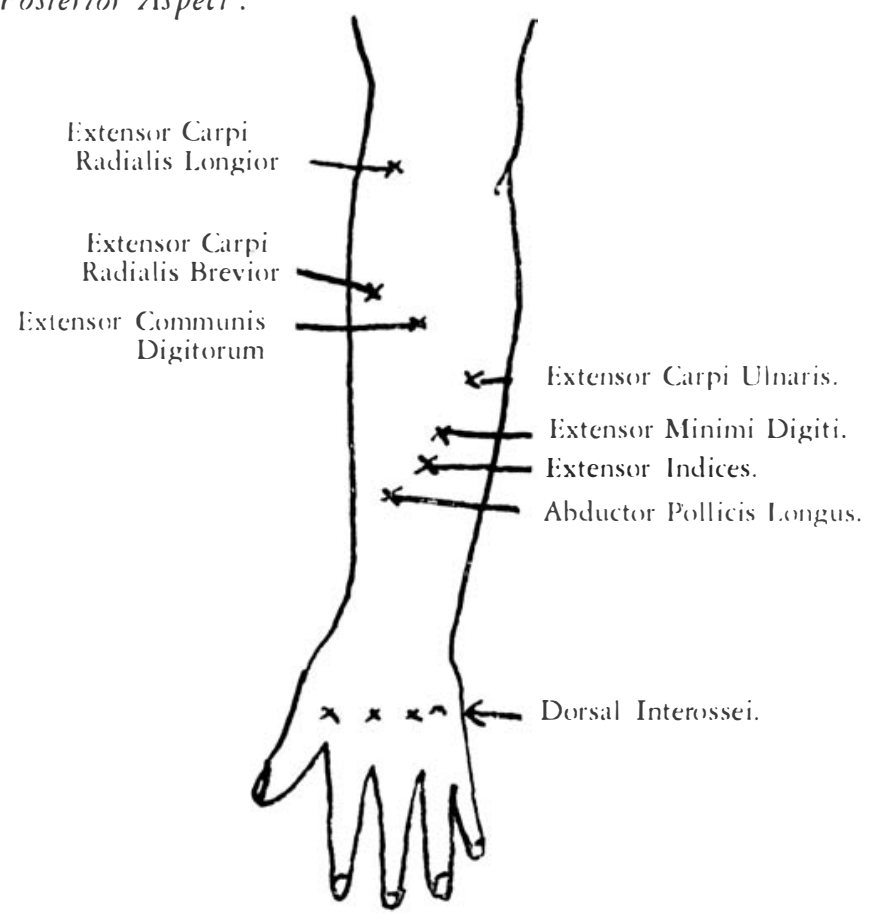

(a) Stroking or Labile la aradism :-The machine should be set at the strength required, and the disc electrode moved firmly up and down the forearm, working from the Radial sicle to the Ulnar side several times on the flexor aspect, and then in the same way on the dorsal aspect.

(b) Surging ladadism:- The disc electrode should be placed on the motor point of one muscle, and the current is "surged" (i.e. gradually increased and graclually clecreased) 6-I 2 times. Then the clisc electrode is placed on the motor point of another muscle and the "surging" repeated, and so on till each muscle has been treated. All the intrinsic muscles of the hand have to be treated in this way, but those of the forearm may be treated by either the labile or surging methods.

To "Surge" the current:- In the machine there will be a thick rod about 6 " in length which fits easily into a hole at the sicle of the machine (if the Smart-Bristow machine is used). This rod is known as the "core." When the core is almost completely withdrawn from the machine the current is weak, and when the core is pushed in to its full length the current is strong.

The core is smoothly pushed in and out 20-40 times a minute, 
allowing complete relaxation of the muscle between each contraction. It is not always necessary to push the core in to its full length, the current need only be sufficiently strong to produce a moderate contraction of the muscle.

7. Conclude this treatment with active hand and finger exercises. N.B. in order to ascertain that the machine is in good working order before treating a patient, the operator should always test the current on himself first.

USES :-

I. To strengthen the muscles.

2. In the event of gradual denervation to work the muscles for the patient and keep them in tone, always hoping that after the period of denervation there will be a period of regeneration. Where this occurs, because muscles have been kept in tone they should (a) regain their strength more quickly than if nothing had been done, and (b) the possibility of flexion deformity and contracture occurring during the period of denervation is more likely to be delayed and possibly averted. 